\title{
Organizational Justice Perceptions as Predictor of Job Satisfaction and Organization Commitment
}

\author{
Arti Bakhshi \\ Associate Professor, P.G. Department of Psychology \\ University of Jammu \\ Jammu 180001 \\ Tel: 91-9419-133-266Ｅ-mail: artibakhshi@gmail.com \\ Kuldeep Kumar (Corresponding author) \\ UGC- Research Fellow, P.G. Department of Psychology \\ University of Jammu \\ Jammu 180001 \\ Tel: 91-9469-212-552 E-mail: kkmalhotra1@yahoo.co.in \\ Ekta Rani \\ S.P.M.R. College of Commerce \\ Jammu 180001 \\ Tel: 91-9469-001-816 E-mail: ektadeep@ymail.com
}

\begin{abstract}
The present study explored the relationship between perceived organizational justice, job satisfaction and organization commitment using a field sample. Sample for the present study consisted of 128 employees working in medical college. Regression analysis of the data obtained indicated that distributive justice was significantly related to job satisfaction whereas procedural justice was not found to be related significantly with job satisfaction. Also both distributive justice and procedural justice were found to be significantly related to organization commitment. Theoretical and practical implications of the results are discussed.
\end{abstract}

Keywords: Perceived organizational justice, Job satisfaction and organization commitment

\section{Introduction}

The study of organizational justice perceptions has received great attention from the researchers and scholars and it has become frequently researched topics in the field of industrial-organizational psychology, human resource management and organization behavior (Cropanzano \& Greenberg, 1997). Over the last 30 years, organizational justice has been researched extensively in social psychology, specifically in organizational contexts by psychologists and management researchers, among others interested in the construct (Blakely, Andrews \& Moorman, 2005; Moorman, 1991; Trevino \& Weaver, 2001). Perceptions of organizational justice constitute an important heuristic in organizational decision-making, as research relates it to job satisfaction, turnover, leadership, organizational citizenship, organizational commitment, trust, customer satisfaction, job performance, employee theft, role breadth, alienation, and leader-member exchange (Cohen Charash \& Spector, 2001). Kim (2009) found that employees who perceived that they were treated fairly by their company tended to develop and maintain communal relationships with the company. Also, when employees felt that they were treated fairly by their company, they were likely to hold more commitment, trust, satisfaction, and control mutuality than when they perceived that they were treated unfairly. 
The research on organization justice perceptions which focuses on the role of fairness in the work place have shown that organizational justice perceptions strongly effect the attitude of the workers such as job satisfaction, turnover intentions and organization commitment and also workplace behavior such as absenteeism and organizational citizenship behavior (Colquitt, Conlon, Wesson, Porter, \& Ng, 2001). In addition, research has also demonstrated the linkages between perceived organizational justice and individual work performance (Colquitt et al., 2001, Earley \& Lind, 1987). Perceived organizational justice is found to be an important antecedent of organizational citizenship behavior (Bakhshi \& Kumar, 2009). Although the associations between justice perceptions and various work outcomes are well established in western literature a very few studies has examined the relationship of justice perceptions with work attitude and work behavior in Indian culture. A number of studies showed that culture do influence the justice perceptions of the employees and culture is an important determinant of what impact does the justice perception will have on various work outcomes. Tyler and his colleagues (Lind \& Tyler, 1988; Tyler, Boeckmann, Smith, \& Huo, 1997) proposed that procedural justice concerns are ubiquitous across diverse societal and cultural settings. Cross-cultural research on procedural justice has recently begun (Brockner, Chen, Mannix, Leung, \& Skarlicki 2000; Lind \& Earley, 1992; Lind, Tyler, \& Huo, 1997). A first question addressed by cross-cultural procedural justice researchers is whether non-Westerners (i.e., collectivists) care about procedural justice issues as well (e.g., LaTour, Houlden, Walker, \& Thibaut, 1976). Similarly, Sugawara and Huo (1994) found that the Japanese show a strong concern about procedural justice in conflict resolutions. White, Tansky, and Baik (1995) reported that Korean subjects reveal concerns about procedural justice, although their concerns are lower than those of American subjects. The present study aims to find the relationship between justice perceptions, job satisfaction an organization commitment and attempt to fill that research gap. We provide a brief review of the conceptualization of the organizational justice construct before reviewing the specific research questions explored in this article.

\subsection{Perceived organizational justice}

When employees react to the way they are treated at work, their motivation to respond cannot be understood adequately without taking into account perceived fairness of the outcomes and the procedure used to reach that outcomes (Folger \& Konovsky, 1989; Greenberg, 1986). The organizational justice construct has been partitioned into at least three factors: distributive justice, procedural justice, and interactional justice. Adams (1965) conceptualized fairness by stating that employees determine whether they have been treated fairly at work by comparing their own payoff ratio of outcomes (such as pay or status) to inputs (such as effort or time) to the ratio of their co-workers. This is called distributive justice, and it presents employees' perceptions about the fairness of managerial decisions relative to the distribution of outcomes such as pay, promotions, etc (Folger \& Konovsky, 1989). In contrast, procedural justice focuses on the fairness of the manner in which the decision-making process is conducted (Folger \& Konovsky, 1989). In other words, the focus shifts from what was decided to how the decision was made (Cropanzano \& Folger, 1991). As a third concept, interactional justice reflects the quality of interpersonal treatment during the implementation of formal procedures of decisions (Bies \& Moag 1986).

\subsubsection{Distributive justice}

Before 1975, the study of justice was primarily concerned with distributive justice. Much of this research was derived from initial work conducted by Adams (1965), who used a social exchange theory framework to evaluate fairness. According to Adams, what people were concerned about was not the absolute level of outcomes per se but whether those outcomes were fair.

Whereas Adams's theory advocated the use of an equity rule to determine fairness, several other allocation rules have also been identified, such as equality and need (e.g., Leventhal, 1976). Studies have shown that different contexts (e.g., work vs. family), different organizational goals (e.g., group harmony vs. productivity), and different personal motives (e.g., self-interest motives vs. altruistic motives) can activate the use or primacy of certain allocation rules (Deutsch, 1975). Nevertheless, all of the allocation standards have as their goal the achievement of distributive justice; they merely attempt to create it through the use of different rules.

\subsubsection{Procedural justice}

Thibaut and Walker's (1975) research on individuals' reactions to dispute resolution procedures led to the development of procedural justice theory, which is concerned with judgments about the process or means by which allocation decisions are made. Although Thibaut and Walker (1975) introduced the concept of procedural justice, their work focused primarily on disputant reactions to legal procedures. Leventhal and colleagues can be credited for extending the notion of procedural justice into nonlegal contexts such as organizational settings (Leventhal, 1980; Leventhal et al., 1980). In doing so, Leventhal and colleagues also broadened the list of determinants of procedural justice far beyond the concept of process control. Leventhal's theory of procedural justice judgments focused on six criteria that a procedure should meet if it is to be perceived as fair. Procedures should (a) be applied consistently across people and across time, (b) be free from bias (e.g., ensuring that a third party has no vested interest in a particular settlement), (c) ensure that accurate information is collected and used in making decisions, (d) have some mechanism to correct flawed 
or inaccurate decisions, (e) conform to personal or prevailing standards of ethics or morality, and (f) ensure that the opinions of various groups affected by the decision have been taken into account.

\subsubsection{Interactional Justice}

Bies and Moag (1986) introduced the most recent advance in the justice literature by focusing attention on the importance of the quality of the interpersonal treatment people receive when procedures are implemented. Bies and Moag (1986) referred to these aspects of justice as "interactional justice." More recently, interactional justice has come to be seen as consisting of two specific types of interpersonal treatment (e.g., Greenberg, 1990a, 1993b). The first, labeled interpersonal justice, reflects the degree to which people are treated with politeness, dignity, and respect by authorities or third parties involved in executing procedures or determining outcomes. The second, labeled informational justice, focuses on the explanations provided to people that convey information about why procedures were used in a certain way or why outcomes were distributed in a certain fashion.

Justice perceptions also have been linked to important outcome variables (Dailey \& Kirk, 1992; Folger \& Konovsky, 1989; Martin \& Bennett, 1996; McFarlin \& Sweeney, 1992). For instance, perceptions of procedural justice are negatively related to intentions to quit (Dailey \& Kirk, 1992), significantly correlate with organizational commitment (Folger \& Konovsky, 1989; Martin \& Bennett, 1996), and produce high subordinates' evaluation of supervisors (McFarlin \& Sweeney, 1992). In other words, if employees perceive that the decision making process is fair, they are less likely to form an intention to quit. On the other hand, distributive justice perceptions are associated with pay raise satisfaction (Folger \& Konovsky, 1989), and tend to be a strong predictor of job satisfaction (Martin \& Bennett, 1996; McFarlin \& Sweeney, 1992). Greenberg (1990) also reports that organizational justice, which refers to people's perceptions of the fairness of treatment received from organizations, is important as a basic requirement for the effective functioning of organizations.

\subsection{Job Satisfaction}

Job satisfaction or Employee Satisfaction (also referred to as morale) is one of the most used variables in Organizational Behavior. It is an employee's attitudinal response to his or her organization. As an attitude, job satisfaction is conceptualized as consisting of evaluative, cognitive and affective components.

The Evaluative Component- An individual's overall response to the employing organization is summarized in the evaluative component. It represents dislike vs. like for the organization.

The Cognitive Component- An individual's perceptions, opinion, beliefs and expectations regarding the organization are the focus of his or her cognitions. Employees hold cognitions about each of the four major inducement systems. Cognitions in which the individual perceives that his or her expectations have been met generally lead to positive evaluations. Additionally, positive evaluations are more likely when cognitions (expectations) support a positive and secure future with the organization.

The Affective Component- This represents the feeling evoked by the organization. Does thinking about and association with the organization evoke pleasurable or uncomfortable feelings; feelings of anger or joy; feelings of security or stress; feelings of affirmation or invalidation? In general, positive affect results from information, feedback, and situations that affirms or reinforces the individual's self worth and self-concept, while negative affect is evoked by invalidating situations. Self worth is validated when individuals feel accepted as values members of the organization and their competencies and core values are affirmed. When individuals are in a positive affect state while working, they tend to evaluate the organization positively.

\subsection{Organization commitment}

Organizational commitment has been identified as a critical factor in understanding and explaining the work-related behavior of employees in organizations. Most definitions of organizational commitment describe the construct in terms of the extent to which an employee identifies with and is involved with an organization (Curry, Wakefield, Price, \& Mueller, 1986). For example, Steer (1977) defined organizational commitment as the relative strength of an individual's identification with and involvement in a particular organization. Mowday et al. (1979) defined organizational commitment as an affective response which moves beyond passive loyalty to an organization. Porter, Steers, Mowday, and Boulian (1974) identified three related factors of organizational commitment: (1) a strong belief in an organization's goals and values, (2) a willingness to exert considerable effort for the organization, and (3) a strong desire to maintain membership in the organization. Meyer and Allen (1991) argued that the psychological states reflected in these different definitions of organizational commitment are not mutually exclusive. They referred to these states as components of organizational commitment. These include affective commitment (emotional attachment), continuance commitment (cost-based), and normative commitment (obligation). Mathieu and Zajac (1990) noted that the various definitions and measures share a common theme in that organizational commitment is considered to be a bond or linking of the individual to the organization. 
2. Hypothesized relationship between perceived organizational justice; organizational commitment and job satisfaction

Many studies also ask about employees' satisfaction with their jobs in general. McFarlin and Sweeney (1992) showed that distributive justice was a more powerful predictor of job satisfaction than was procedural justice. Distributive justice, however, is a better predictor of personal outcomes such as pay satisfaction. However, this does not seem to fit the two-factor theory argument that procedural justice predicts system-referenced outcomes, whereas distributive justice predicts person-referenced outcomes. In addition, Masterson, Lewis, Goldman \& Taylor (2000) showed procedural justice to be a stronger predictor of job satisfaction than interactional justice, although both had significant independent effects. Organizational commitment represents a global, systemic reaction that people have to the company for which they work. Perceived organization justice is an important predictor of job satisfaction as well as organization commitment. One reason for this could be that use of fair procedures in decision making provides evidence of a genuine caring and concern on the part of the organization for the well being of employees (Lind \& Tyler, 1988). This in turn motivates the employees to continue their association with their current organization. Thus in this research it was hypothesized that if the employees perceived both distributive justice and procedural justice to be high they would be more motivated to continue their association with their current institutions and would show higher job satisfaction level.

Hypothesis 1: Distributive justice will positively relate to job satisfaction.

Hypothesis 2: Procedural justice will positively relate to job satisfaction.

Hypothesis 3: Distributive justice will positively relate to organizational commitment.

Hypothesis 4: Procedural justice will positively relate to organizational commitment.

3. Methodology

\subsection{Sample}

Sample for the present study consisted of 128 employees working in medical college. A 67.36\% response rate (128 out of 190 possible respondents) was obtained. The gender composition of the sample was $61.71 \%$ male $(\mathrm{N}=79)$ and $38.28 \%$ female $(\mathrm{N}=49)$. The average age of the respondents was 30.40 years $(\mathrm{SD}=3.25)$. On average, respondents had worked in their present jobs for 32.05 months $(\mathrm{SD}=25.31)$.

\subsection{Variables}

Control variable: Age, Gender and Job Tenure

Predictor Variable: Distributive Justice and Procedural Justice

Criterion Variable: Job Satisfaction and Organization Commitment

\subsection{Measurements}

\subsubsection{Distributive Justice Index}

Perceptions of distributive justice will be measured with the Distributive Justice Index, developed by Price and Mueller (1986). A sample item states "My supervisor has fairly rewarded me when I consider the responsibilities I have". All reliabilities reported have been above .90 , and the scale has shown discriminant validity in relation to job satisfaction and organizational commitment (Moorman, 1991).

\subsubsection{Procedural Justice Scale}

Perceptions of procedural justice will be measured using 15 item scale developed by Niehoff and Moorman (1993). A sample item states "Job decisions are made by my supervisor in an unbiased manner". Moorman (1999) has reported reliability above .90 .

\subsubsection{Job satisfaction}

Job satisfaction was measured using job satisfaction scale developed by Singh and Sharma (1999). The scale consisted of thirty items and each item has five alternatives and the respondent has to choose one option which candidly expresses his response. The mean score of all the items represent the job satisfaction level of the individual employee. A sample item states "With regard to post retirement benefits, like pension, gratuity, etc., I rate my job as .........." the test-retest reliability of the scale is reported to be 0.978 with $\mathrm{N}=52$ and a gap of 25 days.

\subsubsection{Organizational commitment}

Organizational commitment was measured by the nine-item short version of the Organizational Commitment Questionnaire (OCQ) developed by Porter et al., (1974). There is a seven-point response dimension. A sample item states "I talk up this organization to my friends as a great organization to work for". Item scores are summed and the mean is taken. Thus, there is a possible range of scores from one to seven, and the higher the score the more organizationally committed an individual is judged to be. Reliability and validity evidence has been provided by Porter 
et al., (1974), Steers (1977), Steers and Spencer (1977), and Stone and Porter (1975). The coefficient alpha is consistently high in the studies, ranging from 0.82 to 0.93 with a median of 0.90 .

\section{Results}

Table 1 lists the means, standard deviations, intercorrelations, and reliabilities for the variables. The correlations among some of the study variables provided initial support for our hypotheses. In support of Hypothesis 1, Distributive justice was positively correlated with job satisfaction $(\mathrm{r}=.61, \mathrm{p}<.01)$. In addition, procedural justice was positively correlated with job satisfaction $(\mathrm{r}=.59, \mathrm{p}<.01)$, providing support for Hypothesis 2 . Distributive justice was also positively correlated with Organization commitment $(\mathrm{r}=.91, \mathrm{p}<.01)$, providing support for Hypothesis 3 . Finally, procedural justice was positively correlated with Organization commitment $(\mathrm{r}=.60, \mathrm{p}<.01)$, supporting Hypothesis 4 .

\section{REFER TO TABLE 1 IN APPENDIX}

To test our hypotheses, we performed a hierarchical regression analysis for each of the outcome variable i.e. job satisfaction and organization commitment. Our goal was to determine if the hypothesized variables added a unique contribution in the prediction of the criterion above and beyond the control variables. As such, we first entered the control variables. Second, we entered the distributive justice and procedural justice. To control for potential demographic effects, we included age, gender and job tenure as control variables. In the description below of our results, all reported coefficients are standardized and adjusted $\mathrm{R}^{2} \mathrm{~s}$ are reported.

\section{REFER TO TABLE 2 IN APPENDIX}

\section{REFER TO TABLE 3 IN APPENDIX}

$\mathrm{R}^{2}$ is the measure of how much of the variability in the outcome variable is accounted for by the predictors. For the model 1 its value is 0.436 which means that control variables (age, gender and job tenure) accounts for $43.6 \%$ of the variation in job satisfaction. However for the final model (model 2) this value increases to 0.557 or $55.7 \%$ of the variation in job satisfaction. Table 2 shows that, as a set of predictors, Distributive Justice and Procedural Justice explained an additional $12 \%$ of variance in the criterion over and above the control variables $(\Delta \mathrm{F}=16.52, \mathrm{p}<.01)$. Specifically, as shown in table 3 distributive justice significantly related to job satisfaction $(\beta=.32, p<.01)$ supporting Hypothesis 1. Table 3 also shows that procedural justice was not found to relate to job satisfaction $(\beta=.11, p>.1)$, providing no support for Hypothesis 2.

\section{REFER TO TABLE 4 IN APPENDIX}

\section{REFER TO TABLE 5 IN APPENDIX}

As shown in Table $4 \mathrm{R}^{2}$ for the model is 0.935 which means that control variables (age, gender and job tenure) accounts for $93.5 \%$ of the variation in organization commitment. However for the final model (model 2) this value increases to 0.953 or $95.3 \%$ of the variation in job satisfaction. Thus, as a set of predictors, Distributive Justice and Procedural Justice explained an additional $1.7 \%$ of variance in the criterion over and above the control variables $(\Delta \mathrm{F}=21.95, \mathrm{p}$ $<.01)$. Specifically, as shown in table 5 distributive justice significantly related to organization commitment $(\beta=.42, \mathrm{p}$ $<.01)$ supporting Hypothesis 3 . It also shows that procedural justice was found to relate to organization commitment $(\beta=.10, \mathrm{p}<.01)$, providing support for Hypothesis 4 .

\section{Discussion}

The present study attempted to link perceived organizational justice with job satisfaction and organization commitment. Distributive justice was found to be positively related to both job satisfaction and organization commitment. Consistent with this prediction, McFarlin and Sweeney (1992) found that distributive justice was a more important predictor of what they termed two "personal outcomes" (pay satisfaction and job satisfaction) and that procedural justice was a more important predictor of two "organizational outcomes" (organizational commitment and subordinate's evaluation of supervisor). Other studies have shown high correlations between procedural justice and job satisfaction (e.g., Mossholder, Bennett, \& Martin, 1998; Wesolowski \& Mossholder, 1997). In addition, Masterson, Lewis, Goldman and Tyalor (2000) showed procedural justice to be a stronger predictor of job satisfaction than interactional justice, although both had significant independent effects.

In addition Procedural justice was not found to be related to job satisfaction but it was significantly related to organization commitment. Prior work by Tyler (e.g., Tyler, 1990) argues that procedural justice has stronger relationships with support for institutions than does distributive justice. However, we should note that several studies have instead supported the distributive dominance model. For example, Lowe and Vodanovich (1995) found a stronger relationship for distributive justice and organizational commitment than for procedural justice, as did Greenberg (1994).

\subsection{Theoretical and practical implications}

The present study attempts to explore the relationship between perceived organizational justice, job satisfaction and organization commitment. Theoretically, the current results suggest that an organization justice perception plays an 
important role in the development of organizational commitment and job satisfaction. Perceived organizational justice was expected to correlate significantly with both job satisfaction and organization commitment. Those who perceive justice in their organization are more likely to feel satisfied with their job and feel less likely to leave and feel more committed to their job. The current study will provide the administrators and policy makers with insights into the relationship between perceived organizational justice and work attitudes and the formations of employees' justice perceptions, and with insights into how to manage employees using organizational justice perspective to draw positive attitudinal and behavioral reactions from employees. The present study will help them better understand how to retain valuable employees, increase employees' commitment to and satisfaction with their work, reduce employee turnover, and improve the performance of the employees.

\subsection{Limitations}

Like all research, there are limitations to this study that must be taken into consideration. First, the data were cross-sectional in nature and this restriction prevents the inference of causality. At a minimum, a longitudinal design is required to infer any causality that may exist among these variables. Second, the results may have been affected by common method variance because all of our data were collected from self-report measures. Because measures come from same source, any defect in that source, any defect in that source contaminates measures, presumably in the same fashion and in the same direction. A primary concern of common method variance is that the relationships observed between variables may be due to the measurement method rather than the hypothesized relationships between constructs (Podsakoff \& Organ, 1986). However, Saalancik and Pfeffer (1977) has suggested that one possible technique that could be used to reduce common method variance is to reorder the items on the questionnaire such that dependent or criterion variable follows, rather than precedes, the independent variable. This method was followed in the design of our questionnaire. Finally, the effect sizes for the relationships of interest were relatively small. This suggests the possibility of unknown moderator or mediator variables on the perceived organization justice-commitment and job satisfaction relationship. Organizational variables such as job characteristics, rewards, and other contextual variables may be of particular relevance because each of these variables is a potential antecedent of organization commitment and job satisfaction. Unfortunately, data were not collected in regard to possible moderators or mediators because such hypotheses were beyond the scope of this study.

\section{References}

Adams, J. S. (1965). Inequity in social exchange. In L. Berkowitz (Ed.), Advances in experimental social psychology (Vol. 2, pp 267-299), New York: Academic Press

Bakhshi, A. \& Kumar, K. (2009). National culture and organizational citizenship behavior: Development of a scale. In Singh, S. (Ed.), Organisation Behaviour . Global Publishing House: New Delhi.

Bies, R. J., \& Moag, J. (1986). Interactional justice: Communication criteria of fairness. In R. J. Lewicki, B. H. Sheppard, \& M. Bazerman (Eds.), Research on negotiation in organizations (Vol. 1, pp. 43-55). Greenwich, CT: JAI Press.

Blakely, G., Andrews, M., \& Moorman, R. (2005). The moderating effects of equity sensitivity on the relationship between organizational justice and organizational citizenship behavior. Journal of Business Psychology, 20(2), 259-273.

Brockner, J., Chen, Y. R., Mannix, E. A., Leung, K., \& Skarlicki, D. P. (2000). Culture and procedural fairness: When the effects of what you do depend on how you do it. Administrative Science Quarterly, 45, 138-159.

Cohen-Charash, Y., \& Spector, P. E. (2001). The role of justice in organizations: A meta-analysis. Organizational Behavior and Human Decision Processes, 86, 278-321.

Colquitt, J. A., Conlon, D. E., Wesson, M. J., Porter, C. O., \& Ng, K. Y. (2001). Justice at the millennium: A meta-analytic review of 25 years of organizational justice research. Journal of Applied Psychology, 86, 425- 445.

Cropanzano, R., \& Greenberg, J. (1997). Progress in organizational justice: Tunneling through the maze. In C. Cooper \& I. Robertson (Eds.), International review of industrial and organizational psychology (pp. 317-372). New York: Wiley.

Curry, J. P., Wakefield, D. S., Price, J. L., \& Mueller, C. W. (1986). On the causal ordering of job satisfaction and organizational commitment. Academy of Management Journal, 29(4), 847-858.

Dailey, R. C., \& Kirk, D. J. (1992). Distributive and procedural justice as antecedents of job dissatisfaction and intent to turnover. Human Relations, 45(3), 305-317.

Deutsch, M. (1975). Equity, equality, and need: What determines which value will be used as the basis of distributive justice? Journal of Social Issues, 31, 137-150.

Earley, P. C., \& Lind, E. A. (1987). Procedural justice and participation in task selection: The role of control in mediating justice judgments. Journal of Personality and Social Psychology, 52, 1148-1160. 
Folger, R., \& Cropanzano, R. (1998). Organizational Justice and Human Resources Management. Thousand Oaks, London: Sage Publications.

Folger, R., \& Konovsky, M. A. (1989). Effects of procedural and distributive justice on reactions to pay raise decisions. Academy of Management Journal, 32(1), 115-130.

Greenberg, J. (1986). Determinants of perceived fairness of performance evaluations. Journal of Applied Psychology, $71,340-342$.

Greenberg, J. (1990). Employee theft as a reaction to underpayment inequity: The hidden cost of pay cuts. Journal of Applied Psychology, 75, 561-568.

Greenberg, J. (1990). Organizational justice: Yesterday, today, and tomorrow. Journal of Management, 16, 399-432.

Greenberg, J. (1994). Using socially fair treatment to promote acceptance of a work site smoking ban. Journal of Applied Psychology, 79, 288- 297.

Kang, D. (2007). Perceived Organisational Justice as a Predictor of Employees' Motivation to Participate in Training. Research and Practice in Human Resource Management, 15(1), 89-107.

Kim, H. (2009). "Integrating Organizational Justice into the Relationship Management Theory". Retrieved from [Online] Available: http://www.allacademic.com/ (Retrieved from $15^{\text {th }}$ of May 2009).

LaTour, S., Houlden, P., Walker, L., \& Thibaut, J. W. (1976). Procedure: Transnational perspectives and preferences. Yale Law Journal, 86,258-290.

Leventhal, G. S. (1976). The distribution of rewards and resources in groups and organizations. In L. Berkowitz \& W. Walster (Eds.), Advances in experimental social psychology (Vol. 9, pp. 91-131). New York: Academic Press.

Leventhal, G. S. (1980). What should be done with equity theory? New approaches to the study of fairness in social relationships. In K. Gergen, M. Greenberg, \& R. Willis (Eds.), Social exchange: Advances in theory and research (pp. 27-55). New York: Plenum.

Leventhal, G. S., Karuza, J., \& Fry, W. R. (1980). Beyond fairness: A theory of allocation preferences. In G. Mikula (Ed.), Justice and social interaction (pp. 167-218). New York: Springer-Verlag.

Lind, E. A., \& Earley, P. C. (1992). Procedural justice and culture. International Journal of Psychology, 27, 227-242.

Lind, E. A., \& Tyler, T. R. (1988). The social psychology of procedural justice. New York: Plenum.

Lind, E. A., Tyler, T. R., \& Huo, Y. (1997). Procedural context and culture: Variation in the antecedents of procedural justice judgments. Journal of Personality and Social Psychology, 73, 767- 780.

Lowe, R. H., \& Vodanovich, S. J. (1995). A field study of distributive and procedural justice as predictors of satisfaction and organizational commitment. Journal of Business and Psychology, W, 99-114.

Martin, C. L., \& Bennett, N. (1996). The role of justice judgments in explaining the relationship between job satisfaction and organizational commitment. Group \& Organizational Management, 21(1), 84-104.

Masterson, S. S., Lewis, K., Goldman, B. M., \& Taylor, M. S. (2000). Integrating justice and social exchange: The differing effects of fair procedures and treatment on work relationships. Academy of Management Journal, 43, 738-748.

Mathieu, J. E., \& Zajac, D. M. (1990). A review and meta-analysis of the antecedents, correlates, and consequences of organizational commitment. Psychological Bulletin, 108(2), 171-194.

McFarlin, D. B., \& Sweeney, P. D. (1992). Distributive and procedural justice as predictors of satisfaction with personal and organizational outcomes. Academy of Management Journal, 35(3), 626-637.

Meyer, J. P., \& Allen, N. J. (1991). A three-component conceptualization of organizational commitment. Human Resource Management Review, 1(1), 61-89.

Moorman, R. H. (1991). Relationship between organizational justice and organizational citizenship behaviors: Do fairness perceptions influence employee citizenship? Journal of Applied Psychology, 76(6), 845-855.

Mossholder, K. W., Bennett, N., \& Martin, C. L. (1998). A multilevel analysis of procedural justice context. Journal of Organizational Behavior, 19, 131-141.

Mowday, R. T., Steers, R. M., \& Porter, L. W. (1979). The measurement of organizational commitment. Journal of Vocational Behavior, 14, 224-247.

Niehoff, B.P. \& Moorman, R.H. (1993). Justice as a mediator of the relationship between methods of monitoring and organizational citizenship behavior. Academy of Management Journal, 36, 527-556.

Porter, L. W., Steers, R. M., Mowday, R. T., \& Boulian, P. V. (1974). Organizational commitment, job satisfaction, and turnover among psychiatric technicians. Journal of Applied Psychology, 59, 603-609. 
Price, J. L., \& Mueller, C. W. (1986). Handbook of Organizational Measurement. Marshfield, MA: Pittman.

Salancik, G.R., \& Pfeffer, J. (1977). An examination of need-satisfaction model of job attitudes. Administrative Science Quarterly, 22, 427-456.

Singh, A. \& Sharma, T.R. (1999). Manual for Job Satisfaction Scale. National Psychological Corporation: Agra

Steers, R. M. (1977). Antecedents and outcomes of organizational commitment. Administrative Science Quarterly, 22 , 46-56.

Steers, R. M., \& Spencer, D. G. (1977). The role of achievement motivation in job design. Journal of Applied Psychology, 62(4), 472-479.

Stone, E. F., \& Porter, L. W. (1975). Job characteristics and job attitudes: A multivariate study. Journal of Applied Psychology, 60(1), 57-64.

Sugawara, I., \& Huo, Y. J. (1994). Disputes in Japan: A cross-cultural test of the procedural justice model. Social Justice Research, 7,129-144.

Thibaut, J., \& Walker, L. (1975). Procedural justice: A psychological analysis. Hillsdale, NJ: Erlbaum.

Trevino, L. \& Weaver G. (2001). Organizational justice and ethics program "follow-through": Influences on employees' harmful and helpful behavior. Business Ethics Quarterly, 11(4), 651-671.

Tyler, T. R. (1990). Why people obey the law: Procedural justice, legitimacy, and compliance. New Haven, CT: Yale University Press.

Tyler, T. R., Boeckmann, R. J., Smith, H. J., \& Huo, Y. J. (1997). Social justice in a diverse society. Boulder, CO: Westview Press.

Wesolowski, M. A., \& Mossholder, K. W. (1997). Relational demography in supervisor subordinate dyads: Impact on subordinate job satisfaction, burnout, and perceived procedural justice. Journal of Organizational Behavior, 18, 351-362.

White, M. M., Tansky, J. A., \& Baik, K. (1995). Linking culture and perception of justice: A comparison of students in Virginia and South Korea. Psychological Reports, 77, 1103-1112.

Appendix

Table 1. Means, standard deviations, intercorrelations, and coefficient alphas of study variables

\begin{tabular}{|c|c|c|c|c|c|}
\hline Variables & Mean & SD & 1 & 4 & 2 \\
\hline Age & 30.40 & 3.25 & & & \\
\hline Gender & .61 & .48 & & & \\
\hline $\mathrm{J} \mathrm{T}$ & 32.05 & 25.31 & & & \\
\hline 1. DJ & 23.37 & 4.38 & $(.82)$ & & \\
\hline 2. $\mathrm{PJ}$ & 61.85 & 7.18 & $.66^{*}$ & $(.86)$ & \\
\hline 3. JS & 74.16 & 8.82 & $.61 * *$ & $.59 * *$ & $(.83)$ \\
\hline 4. $\mathrm{OC}$ & 33.29 & 8.29 & $.91 * *$ & $.60 * *$ & $.51 * *$ \\
\hline
\end{tabular}

Note: JT- Job Tenure (in months completed); DJ- Distributive Justice; PJ- Procedural Justice; JS- Job Satisfaction; OCOrganizational Commitment.

Note: $\mathrm{N}=128$.

$* \mathrm{p}<.05$.

$* * \mathrm{p}<.01$ (two-tailed). 
Table 2. Hierarchical Regression for job satisfaction, control variables and perceived Organizational Justice (Distributive and Procedural)

\begin{tabular}{|c|c|c|c|c|}
\hline Model & $\mathrm{R}$ & R Square & Adjusted R Square & R Square Change \\
\hline 1 & $.661^{\mathrm{a}}$ & .436 & .423 & $.436^{* *}$ \\
2 & $.746^{\mathrm{b}}$ & .557 & .538 & $.120^{* *}$ \\
\hline
\end{tabular}

Note: $\mathrm{N}=128$

$* * \mathrm{p}<.01$.

Predictors: (Constant), Gender, Age, Job tenure

Predictors: (Constant), Gender, Age, Job tenure, Procedural justice, Distributive Justice

Job satisfaction

Table 3.

\begin{tabular}{|c|c|c|c|}
\hline Model & $\mathrm{b}$ & SE b & $\beta$ \\
\hline Step 1 & -16.03 & 10.47 & \\
Constant & 9.10 & 2.13 & $.50^{* *}$ \\
Gender & 2.82 & 0.32 & $.04^{* *}$ \\
Age & -0.03 & 0.03 & -0.10 \\
Job Tenure & & & \\
Step 2 & 14.77 & 10.80 & \\
Constant & 11.92 & 2.29 & $.67^{* *}$ \\
Gender & -0.62 & 0.67 & -0.23 \\
Age & -0.02 & 0.03 & -.06 \\
Job Tenure & 2.69 & 0.51 & $.32^{* *}$ \\
Distributive Justice & 0.14 & 0.12 & 0.11 \\
Procedural Justice & & & \\
\hline
\end{tabular}

Note: $\mathrm{N}=128$

$* * \mathrm{p}<.01$. 
Table 4. Hierarchical Regression for Organization commitment, control variables and perceived Organizational Justice (Distributive and Procedural)

\begin{tabular}{|c|c|c|c|c|}
\hline Model & R & R Square & Adjusted R Square & R Square Change \\
\hline 1 & $.967^{\mathrm{a}}$ & .935 & .934 & $.935^{* *}$ \\
2 & $.976^{\mathrm{b}}$ & .953 & .951 & $.017^{* *}$ \\
\hline
\end{tabular}

Note: $\mathrm{N}=128$

$* * \mathrm{p}<.01$.

Predictors: (Constant), Gender, Age, Job tenure

Predictors: (Constant), Gender, Age, Job tenure, Procedural justice, Distributive Justice

Organization commitment

Table 5.

\begin{tabular}{|c|c|c|c|}
\hline Model & $\mathrm{b}$ & SE b & $\beta$ \\
\hline Step 1 & -40.54 & 3.32 & \\
Constant & -0.03 & 0.68 & -0.002 \\
Gender & 2.42 & 0.10 & $0.65^{* *}$ \\
Age & 0.008 & 0.10 & 0.03 \\
Job Tenure & & & \\
Step 2 & -51.08 & 3.32 & \\
Constant & 0.25 & 0.70 & -0.02 \\
Gender & 3.62 & 0.21 & $.42^{* *}$ \\
Age & 0.002 & 0.009 & 0.006 \\
Job Tenure & -0.782 & 0.156 & $0.42^{* *}$ \\
Distributive Justice & -0.12 & 0.04 & $0.10^{* *}$ \\
Procedural Justice & & & \\
\hline
\end{tabular}

Note: $\mathrm{N}=128$

$* * \mathrm{p}<.01$. 